\title{
As repercussões das condições de trabalho na organização do trabalho coletivo e (re)elaboração do projeto político-pedagógico na escola básica
}

\author{
Renata Cristina Oliveira Barrichelo Cunha*
}

\begin{abstract}
Resumo
$\mathrm{O}$ artigo sistematiza análises de uma pesquisa interessada em compreender o processo de discussão e (re)elaboração do projeto político-pedagógico da escola básica no contexto das atividades de trabalho pedagógico coletivo. A pesquisa vem sendo desenvolvida em uma escola da rede pública estadual paulista e envolve o acompanhamento do trabalho coletivo dos professores. As transcrições dos encontros são analisadas na perspectiva sócio-histórica e evidenciam que o envolvimento no processo de discussão e (re)elaboração do projeto político-pedagógico da escola não supõe apenas disponibilidade e compromisso dos professores, mas condições de trabalho que favoreçam a participação, engajamento e dedicação a um plano de ação que responda aos problemas identificados em contexto. Os registros de acompanhamento de dois grupos de professores permitem afirmar que as formas de contratação, remuneração e estabilidade dos professores repercutem nas condições de ensino, desenvolvimento profissional docente e, consequentemente, na organização do trabalho coletivo a favor do projeto político-pedagógico.

Palavras-chave: formação centrada na escola; condições de trabalho; trabalho docente coletivo; projeto políticopedagógico.
\end{abstract}

\section{The repercussion of labor conditions on the organization of collective work and (re) elaboration of political and educational project at elementary school}

\begin{abstract}
The article systematizes the analysis of a research interested in understanding the discussion and (re)elaboration process of the political-pedagogic project of the elementary school in the context of the pedagogic collective working activities. The research is being developed in a public state school from Sao Paulo (Brazil), and involves the monitoring of the teachers' collective work. The transcriptions of the meetings are analyzed in a social-historic perspective and shows that the involvement in the discussions and (re)elaboration process of the political-pedagogic project of the school does not assume only the teachers' availability and commitment, but working conditions that favors participation, engagement and dedication to an action plan that responds to the problems identified in that context. The records from monitoring two groups of teachers allow us to affirm that the hiring conditions, compensation and teachers' stability impact on the teaching conditions, professional teachers' development and, therefore, in the collective work organization in favor of the politicalpedagogic project.

Keywords: Teaching focused in school; labor conditions; collective teaching; political-pedagogic project.
\end{abstract}

\section{Introdução}

A discussão apresentada neste artigo problematiza dados de um projeto de pesquisa financiado pelo $\mathrm{CNPq} / \mathrm{Capes}$ que tem como objetivo compreender e analisar o processo de discussão e (re)elaboração do projeto político-pedagógico (PPP) de uma escola básica no contexto das atividades de trabalho pedagógico coletivo (ATPC).

Compreendemos as ATPC como espaços importantes de socialização e articulação de conhecimentos, saberes e práticas dos professores e gestores, ou seja, como oportunidade de formação centrada na escola orientada pela reflexão sobre o PPP.

A formação centrada na escola, segundo Barroso (2003, p.74), é uma formação que faz "do estabelecimento de ensino o lugar onde emergem as actividades de formação dos seus profissionais, com o fim de identificar problemas, construir soluções e definir projectos". Nesse sentido, o PPP deve constituir-se como pauta permanente das ATPC na medida em que mobiliza processos de negociação de expectativas e perspectivas e contribui com a construção de plano de ação apoiado no diálogo entre teoria e experiência (CUNHA e OMETTO, 2013).

Se admitirmos que a formação centrada nas experiências dos professores precisa se organizar na forma de projetos de ação para responder aos problemas identificados em contexto (CANÁRIO, 2001), é preciso reconhecer quais condições de trabalho permitem a participação dos professores na definição das prioridades da escola e se sua proposta pedagógica.

Isso porque a elaboração do PPP supõe um

engajamento coletivo para integrar ações

* Endereço eletrônico: renata_bcunha@yahoo.com.br 
dispersas, criar sinergias no sentido de buscar soluções alternativas para diferentes momentos do trabalho pedagógicoadministrativo, desenvolver o sentimento de pertença, mobilizar os protagonistas para a explicitação de objetivos comuns definindo o norte das ações a serem desencadeadas, fortalecer a construção de uma coerência comum, mas indispensável, para que a ação coletiva produza seus efeitos (VEIGA, 2003, p.275).

Partindo desses pressupostos, a pesquisa vem sendo realizada em uma escola da rede pública estadual paulista que atende alunos do Ensino Fundamental II e Ensino Médio. Os pesquisadores acompanham, desde 2012, vários grupos de professores reunidos para ATPC. Cada grupo obedece a uma pauta de discussão discutida coletivamente, reconhecendo que a escola enquanto lugar de trabalho é também lugar de formação.

As análises aqui apresentadas com relação às condições necessárias para que as ATPC contribuam com a (re)elaboração permanente do PPP estão baseadas no acompanhamento de dois grupos de professores reunidos durante os anos de 2012 e 2013.

\section{O caminho percorrido na pesquisa}

A pesquisa vem sendo desenvolvida em uma escola da rede pública estadual paulista que atende, aproximadamente, 1000 alunos do Ensino Fundamental II e Ensino Médio, divididos em três períodos. Segundo caracterização do PPP de 2011, a unidade escolar está inserida numa comunidade bastante carente, e muitos moradores e pais de alunos não têm uma profissão definida, o que os obriga a trabalhar em vários serviços temporários e informais. Parte das famílias é atendida pelos programas sociais do governo federal (Bolsa Família e Passe Escolar), além de contar com programas municipais.

Desde a apresentação da proposta da pesquisa ao grupo, no inicio de 2012, as ATPC vêm sendo concebidas como oportunidades de formação e pesquisa em que pesquisadores externos e professores da escola se reúnem para compartilhar, discutir, confrontar e produzir em colaboração conhecimentos e saberes da própria formação e exercício da profissão.

Assumimos a perspectiva de parceria colaborativa na concepção de Giovani (1998), que a compreende como um processo de formação continuada de professores e pesquisadores, com ênfase no trabalho coletivo, capaz de articular questões práticas e problemas teóricos que, mediante um processo de estudo e investigação, pode ampliar o conhecimento e a compreensão da realidade escolar e favorecer o desenvolvimento dos vários profissionais.

As ATPC de 2012 e 2013 foram organizadas em três horários ao longo da semana, com 100 minutos cada, e a participação dos professores variou de acordo com sua carga horária de aulas na escola e jornada de trabalho.

A depender de sua forma de contratação, os professores desses grupos são efetivos, categoria $\mathrm{F}$ ou categoria $\mathrm{O}$. Os professores efetivos ingressaram por concurso e têm aulas atribuídas na escola, gozando de estabilidade. Os professores da categoria $F$ não são concursados, mas têm estabilidade regida pelo Estatuto do Funcionário Público, podendo ou não continuar na escola de um ano para outro, dependendo do número de aulas e da quantidade de professores titulares na escola. Os da categoria $\mathrm{O}$ são professores temporários contratados por períodos menores do que um ano, sem vínculo estatutário, podendo assumir as aulas de fevereiro a novembro, sendo cessados inadiavelmente no último dia letivo.

Os pesquisadores participaram, quinzenalmente, de encontros com os três grupos da escola, mas analisamos nesse artigo dois deles, identificados como Grupo A e Grupo B. O percurso de trabalho (13 encontros com o Grupo A e 12 encontros com o Grupo B) foi registrado em diário de campo e também em áudio para transcrição e análise. O Grupo A, a partir de determinadas condições, produziu coletivamente um "Caderno de Registros" sistematizando as experiências e reflexões dos professores.

A dinâmica desses encontros variou em relação ao tema, encaminhamentos etc. Essas diferenças serão apresentadas juntamente com as análises, uma vez que estão diretamente relacionadas às condições de trabalho dos professores.

A investigação, orientada pela perspectiva sócio-histórica, tem como ênfase a pesquisa no/do/com o cotidiano escolar, compreendido na perspectiva de Heller (2000, p.17) como

a vida do homem inteiro; ou seja, o homem participa na vida cotidiana com todos os aspectos de sua individualidade, de sua personalidade. Nela, colocam-se 'em funcionamento' todos os seus sentidos, todas as suas capacidades intelectuais, suas habilidades manipulativas, seus sentimentos, paixões, ideias, ideologias. 


\section{projeto político-pedagógico na escola básica}

Admitimos que esse cotidiano é constituído por subjetividades inscritas em determinadas circunstâncias histórico-sociais, ou seja, que o cotidiano da escola é articulado de maneira dialética com a formação social.

Ezpeleta e Rockwell (1986) destacam a importância de reconhecermos a educação como uma trama que vai sendo construída permanentemente a partir da articulação entre histórias pessoais e coletivas situadas em determinado contexto social. Isso significa analisar as experiências cotidianas de trabalho coletivo na escola na perspectiva de sua heterogeneidade, considerando que estão impregnadas de conteúdo histórico.

Desse modo, faz-se necessário focalizar o particular como instância da totalidade social e compreender os sujeitos na relação com seus contextos (FREITAS, 2002).

\section{O sentido da escola e do trabalho coletivo: o "PPP em ação"}

A discussão sobre o PPP implica interrogar o sentido da escola, e para tanto Canário (2006) e Fullan e Hargreaves (2001) contribuem para a ampliação da temática.

Canário (2006) busca compreender a chamada "crise da educação", que, do seu ponto de vista, é uma "crise da escola" e envolve uma "crise de sentido". Segundo o autor, a "crise da educação" decorre do fato de que as certezas e as promessas da escola do século $\mathrm{XX}$ não foram e não serão atendidas diante de um quadro que emerge no "contexto dos efeitos cruzados do acréscimo de qualificações, acréscimo de desigualdades, desemprego estrutural de massas, precariedade no trabalho e desvalorização dos diplomas" (p.17).

Destaca que a hegemonia da forma escolar baseada na revelação, na cumulatividade de informações e na exterioridade, ao oferecer respostas e soluções prontas, fomenta a dicotomia aprender-agir e dissocia o sujeito do trabalho que realiza, provocando a ruptura com a experiência e o sentimento de alienação. Quando se desprezam as experiências que os alunos carregam consigo, o trabalho escolar é destituído de sentido. Do mesmo modo, quando as experiências dos professores não são pontos de partida, passagem e chegada do trabalho coletivo, este pode também perder seu sentido.

Fullan e Hargreaves (2001) discutem como podemos transformar as escolas em espaços mais gratificantes para professores e alunos, já que admitem que os professores vivem experiências cada vez menos satisfatórias e produtivas ao longo das suas carreiras e que os estudantes consideram as escolas locais pouco estimulantes e úteis.

Afirmam a necessidade de os professores trabalharem na perspectiva de uma colegialidade, assumindo o desafio do desenvolvimento de um profissionalismo baseado numa cultura colaborativa e no empenho do grupo na direção da melhoria da aprendizagem dos estudantes. Concordam que as reformas educativas têm fracassado porque ignoram os professores e não reconhecem que os problemas são complexos e não se prestam facilmente a soluções rápidas. Priorizando abordagens estruturais, como a redefinição do currículo e a intensificação da avaliação, as reformas não se ocupam das questões de apoio pedagógico que devem acompanhar a implementação das novas iniciativas. Nesse sentido destacam que as condições de ensino estão diretamente relacionadas às condições de desenvolvimento dos professores e condições de trabalho que interferem na articulação do trabalho coletivo nas escolas.

Acreditamos que o contexto que pode favorecer a colegialidade, no sentido de ensinar e aprender na escola, é o do trabalho coletivo, ou seja, da formação que acontece no contexto de trabalho, "privilegiando a colaboração, a interlocução sobre as práticas, as necessidades e os interesses dos professores que participam da construção e da gestão do plano de formação" (CUNHA e PRADO, 2010 , p.104). Esse plano de formação, porque comprometido com o aprofundamento das discussões sobre as práticas e construção de projetos que respondam aos problemas identificados em contexto tem relação indireta ou indireta com o PPP.

O PPP, segundo Soligo (2007), é expressão de três dimensões diferentes de um processo complexo que nem sempre estão articuladas: o resultado da discussão dos educadores sobre as concepções e propostas que consideram pertinentes desenvolver; o que acontece de fato no cotidiano da escola; e o documento que se elabora por solicitação da Secretaria de Educação. É no contexto das ATPC, por meio da discussão das experiências dos professores e da tematização de suas práticas traduzidas no "PPP em ação" que se pode tentar fazer coincidir as três dimensões apontadas.

Discutir o "PPP em ação", tomando como base o projeto discutido, realizado e registrado por meio do diálogo entre os professores pode possibilitar ao grupo aproximar-se do "currículo em ação", ou seja, do "conjunto das aprendizagens vivenciadas pelos alunos, planejadas ou não pela escola, dentro ou fora da aula e da escola, mas sob a responsabilidade desta, ao longo de sua trajetória escolar" (GERALDI, 1994, p.117). Isso significa se 
apropriar daquilo que ocorre, de fato, nas "situações típicas e contraditórias vividas pelas escolas, com suas implicações e compreensões subjacentes e não o que era desejável que ocorresse e/ou o que era institucionalmente prescrito" (id., p.117).

$O$ fato é que não se pode ignorar que as condições de trabalho do professor afetam a forma de participação dos professores nas ATPC e, consequentemente, a (re)elaboração do PPP.

Para Oliveira e Assunção (2010, p.1), as condições de trabalho "se referem a um conjunto que inclui relações, as quais dizem respeito ao processo de trabalho e às condições de emprego (formas de contratação, remuneração, carreira e estabilidade)". A expressão "condições de trabalho do professor", de acordo com Migliavacca (2010, p.1), "alude aos aspectos sociais, políticos, culturais e educacionais que, em um período histórico dado, delimitam o marco estrutural em que se desenvolve o processo de trabalho do professor". Para a autora, essa ideia de condições rompe com a perspectiva "de uma suposta essência universal imanente ao trabalho docente, procurando focalizar o olhar nas relações de forças que permitem pensar o problema a partir de sua contextualização histórica e geográfica".

Como já apontado por Canário (2006) e Fullan e Hargreaves (2001), é preciso que professores e alunos encontrem sentido no seu trabalho. Migliavacca (2010, p.1) reforça que os professores buscam sentido nas atividades que realizam e que esse sentido "tem a ver com a utilidade social de seus investimentos laborais e com a garantia de ocasiões para aprender e se desenvolver no trabalho".

As ATPC podem constituir-se como oportunidades privilegiadas de significar e ressignificar a profissão e contribuir com o PPP; entretanto nossas análises apontam que não basta contar com a disponibilidade dos professores, pois suas condições de trabalho repercutem na organização das ATPC.

\section{A emergência das possibilidades: o Grupo A}

Dos encontros com o Grupo A, ao longo de 2012, participaram duas pesquisadoras, um bolsista de iniciação científica, a diretora, dois professores coordenadores (PC) e 13 professores.

A temática principal discutida nesses encontros foi definida conjuntamente com os professores e PC e versou sobre a formação de leitores e as contribuições da leitura literária para a constituição da subjetividade. A leitura estava, naquele momento, sendo assumida como eixo articulador do PPP da escola.
As discussões foram pautadas pela socialização das preocupações, experiências e práticas na sala de aula e apoiadas na leitura de textos selecionados pelas pesquisadoras como subsídios para a reflexão do grupo (PETIT, 2009, 2010; KRAMER, 2000).

Entre os professores, 12 eram efetivos e 1 era categoria $\mathrm{O}$. Esses professores efetivos tinham entre 25 e 30 horas/aula na escola, o que permitia que 9 deles se dedicassem unicamente à escola. Os outros 3 efetivos completavam sua jornada em outras escolas da rede pública ou da rede privada. Dado o número de aulas na escola, todos os professores desse grupo cumpriam com as duas horas de ATPC, isto é, participavam desses encontros desde o início até o fim.

Essas condições permitiram um envolvimento e dedicação às reuniões que viabilizaram várias ações. Entre algumas delas, destacamos o registro sistemático das discussões do grupo num "Cadernos de Registros", em regime de revezamento entre os professores, valorizando o registro escrito como documentação do trabalho e meio de aprofundamento das reflexões; a organização de uma Feira Cultural que articulou conteúdos e disciplinas, tomando como eixo de trabalho a leitura; a apresentação da experiência e discussão do conteúdo das ATPC em evento científico (ZANON et al., 2012).

Nesse processo foi sendo possível instituir uma formação que apoiou a discussão do PPP. A ênfase na socialização e revisão das práticas dos professores foi permitindo que assumissem compromissos com práticas coletivas, como pode ser destacado no registro da professora Rosa:

Falar sobre o desenvolvimento da prática de ensino, tornar uma aula interessante, tematizar assuntos com os alunos e levar uma realidade diferente daquilo que eles vivem, mostrar que o conhecimento é um passo fundamental na vida do ser humano, $e$ que a leitura é um mundo no qual podemos sonhar, experimentar e viver sem sair do lugar, esse é o nosso maior desafio. É por isso que estamos aqui, para acharmos o caminho $e$ driblar as adversidades que teremos pela frente (...). Fazer uma ATPC e podermos expor a realidade de nossos problemas do cotidiano, sem nos preocupar com o julgamento já é um grande passo, pois só através do trabalho coletivo, da troca de informações e experiências é que podemos transformar o nosso futuro e de nossos alunos (registro escrito elaborado em 


\section{1/09/2012).}

Do enunciado de Rosa é possível depreender o quanto a oportunidade de compartilhar as angústias e ser acolhida sem receio de julgamentos e críticas é significativa para a professora. A cultura da colegialidade (FULLAN e HARGREAVES, 2001) opõe-se, justamente, à cultura do isolamento docente e prevê a busca por novos sentidos de aprender e ensinar tanto para alunos quanto para professores (CANÁRIO, 2006).

Podemos destacar outra passagem em que a colegialidade a favor da "escola reflexiva" (ALARCÃO, 2000) é valorizada quando a professora Denise descreve outro encontro e valoriza o engajamento dos professores na discussão do dia, a emergência de questões e preocupações comuns, o interesse pelas contribuições dos colegas, a escuta atenta, o "ouvir reflexivo":

A discussão foi calorosa, houve participação de todos e foram levantadas questões que, acredito, muitos já se fizeram, como por exemplo: Por que alguns alunos param de ler ao decorrer da vida acadêmica? Como formar alunos leitores? Como trabalhar a questão de ler por prazer e ler por obrigatoriedade? Como lidar com o paradoxo da rapidez da tecnologia enquanto a leitura demanda tempo $e$ determinação? Posso afirmar que a reunião do dia 27 de março trouxe muitas contribuições. Houve troca de experiências, de aflições; houve ideias divergentes, mas acima de tudo, algo que há muito tempo sentia necessidades nas reuniões - silêncio para ouvir o outro! Um ouvir atento, um ouvir reflexivo e consciência de que depende de nós, professores, a busca constante por formação e determinação para promovermos mudanças em nossos alunos. Sendo o objetivo maior desses encontros a formação dos professores nos espaços coletivos, acredito que iniciamos bem! (registro escrito elaborado em 27/03/2012)

A disponibilidade para estar com os colegas, como se pode inferir, passa pela consideração positiva e respeito pelos pares, bem como pela intencionalidade proposta pelo grupo, que é tocado pelo silêncio, traduzido em escuta e acolhimento.

Cabe destacar que as questões formuladas por Denise foram potencializadas pelas leituras e discussões das teorias de Petit $(2009,2010)$, que problematiza o processo de constituição do jovem como leitor e alguns dos obstáculos que enfrenta nesse caminho. As questões de Denise dialogam com as preocupações da autora:

Compreendemos que por meio da leitura, mesmo esporádica, podem [os jovens] estar mais preparados para resistir aos processos de marginalização. Compreendemos que ela os ajuda a se construir, a imaginar outras possibilidades, a sonhar. A encontrar um sentido. A encontrar mobilidade no tabuleiro social. A encontrar distância que dá sentido ao humor. E a pensar, nesses tempos em que o pensamento se faz raro. Estou convencida de que a leitura, em particular a leitura de livros, pode ajudar os jovens a serem mais autônomos e não apenas objetos de discursos repressivos ou paternalistas. $E$ que ela pode representar uma espécie de atalho que leva de uma intimidade um tanto rebelde à cidadania (PETIT, 2009, p.19).

Como bem destacam Sadalla e Sá-Chaves (2008, p.192), o apoio e a discussão crítica das teorias são fundamentais para a compreensão e para a melhoria de práticas de ensino, de modo que cada professor possa ser ajudado "a compreender o seu próprio pensamento e a refletir criticamente sobre sua prática, construindo e (re)significando seu saber-fazer".

Interrogar-se e interrogar os colegas, ao longo dos encontros, passou a constituir-se como uma sistemática na interação do grupo. Interrogar-se é pôr em questão o que se pensa e o que se faz, duvidar de si e das próprias razões, abrindo possibilidades para uma formação compartilhada.

O fragmento abaixo é representativo desse movimento do grupo de pensar sobre as práticas elaborando questões, que é o que alimenta o "PPP em ação":

Prof. Bruno: percebi que o tema, em grande medida, gravitou em torno da leitura como trabalho ou como ludicidade. Minha pergunta é: onde termina e onde começa o que é da ordem do lúdico e o que é da ordem do trabalho? E gostaria de questionar se o lúdico pode levar ao trabalho e, depois, o trabalho se tornar lúdico [no que diz respeito à leitura].

Prof ${ }^{a}$ Taís: minha pergunta é um pouco mais simples: como mudar a imagem da leitura como sendo atividade pertencente estritamente e apenas à aula de leitura? 
Prof. Cláudio: se o professor é um bom leitor, se ele gosta de leitura, como ele consegue transmitir para o aluno essa empolgação? Seja a leitura de uma notícia etc., independente do tipo de leitura, como ele transmite a empolgação? (transcrição da ATPC de 27/03/2012)

As perguntas recorrentes nos encontros acerca da organização do trabalho pedagógico na sala de aula foram desafiando os professores a pensarem em alternativas, práticas pedagógicas, iniciativas que respondessem à necessidade de estimular a leitura entre os alunos. Interrogar-se e compartilhar as práticas de leitura da sala de aula motivaram muitos professores a experimentar, ensaiar novas possibilidades, ajustando expectativas e avaliando as suas propostas de maneira mais cuidadosa. As reflexões sobre as práticas individuais passaram a dimensionar a necessidade de um projeto coletivo, como se pode observar no diálogo abaixo:

Prof $f^{a}$ Sonia: pois é, mas agora chegarei onde pretendo: achei que uma das coisas mais legais em nossos encontros foi que nós tivemos um momento até então inédito: de estar com colegas que nós somente encontraríamos no corredor, aonde somente iríamos nos cumprimentar ou nos conhecer apenas de nomes ou por conversas muito rápidas. E algo que me enriqueceu muito foi o convívio com o grupo. Pensei também que por conta disso, como ficou muito mais gostoso o estar juntos, o estudar juntos... Porque deveríamos fazer algo onde todos nós estivéssemos unidos pelo mesmo objetivo, sei lá, poderíamos levantar um tema e cada um refletiria sobre como poderia contribuir com esse tema. Acredito que também seria interessante, para essa aproximação, que os alunos mesmos percebessem que o conhecimento não é fragmentado. De repente, estou ministrando minha aula $e$ falo determinada coisa e o aluno diz: Nossa! O professor de Geografia falou algo parecido com que a senhora está falando! Isso é importante, pessoal, para que nossos alunos vão aprendendo a fazer ligações, mobilizar conhecimentos etc. Eu penso em algo nesse sentido.

(...)

Prof. Vagner: acredito que é preciso operar as sugestões aqui levantadas mediante um projeto. Pois, ao longo do conteúdo, a apostila com que trabalhamos não foi feita para ser operada dessa forma (...). Um projeto, um tema a ser desenvolvido... (transcrição da ATPC de19/06/2012)

Vagner, professor de Geografia, e Sonia, de Língua Portuguesa, posicionam-se a favor de um trabalho articulado, menos fragmentado, coerente com uma perspectiva de unidade. Ambos se dão conta de que é preciso superar o currículo oficial e a prescrição do material didático e avançar na direção de um trabalho interdisciplinar. Ir além do currículo oficial significa, de certa maneira, oferecer resistência a uma regulação externa que tem induzido práticas pedagógicas, modelos de gestão e de currículo atreladas às avaliações externas (HYPOLITO e IVO, 2013).

A preocupação dos professores, mediada pelas discussões e leituras, aponta que o PPP tem como enorme desafio envolver a comunidade escolar "no sentido de fazer da escola, não uma instituição produtora de fracassos, coadjuvante da exclusão, e sim uma instituição social promotora da humanização de seus cidadãos" (PEREIRA, 2008, p.339).

\section{Limites para o trabalho coletivo: o Grupo B}

A composição do grupo $\mathrm{B}$, ao longo de 2013, era muito mais heterogênea. Dele fizeram parte 10 professores efetivos, 3 da categoria $F, 8$ da categoria $\mathrm{O}$, além de um $\mathrm{PC}$ e uma pesquisadora. Entre aqueles que faziam parte da categoria $\mathrm{O}$, quatro haviam começado a lecionar na escola naquele ano e três tinham até três anos de experiência na escola. Observa-se que parte desse grupo era ingressante na escola ou tinha pouco tempo de contato com seus pares, associado ao fato de que compunha um grupo de professores que não contava com estabilidade de um ano para outro na escola.

Como já destacado anteriormente, dependendo da carga horária de aulas na escola, cada professor cumpre com uma, duas ou três horas de ATPC semanais. Como as ATPC são planejadas para duas horas/aula, 10 professores desse grupo que precisavam cumprir com apenas uma hora frequentaram o primeiro ou segundo momento das reuniões. Isso significa que não participaram das reuniões completas, comprometendo o acesso às informações, contato com o grupo de colegas e aproveitamento das discussões. Do PC era sempre exigido retomar as discussões da primeira parte da ATPC para os que chegavam no segundo horário e retomar as conclusões do encontro na semana 

projeto político-pedagógico na escola básica

seguinte com os professores que não participaram da parte final da reunião da semana anterior.

O cenário de interrupções e falta de continuidade era agravado pelo fato de que onze professores desse grupo davam aulas em mais de uma escola ou exerciam outra profissão juntamente com a de professor, desdobrando-se em muitas atividades, não participando regularmente das ATPC na escola.

O professor Tomás, ao reconhecer que frequentava pouco as ATPC, justifica sua ausência como decorrente das aulas em outra escola e acúmulo de outras atividades:

Eu tenho uma grande vontade de participar com todos das ATPC, eu até conversei com o coordenador sobre isso. Mas é complicado, eu ministro aulas em mais de duas escolas, praticamente. Além disso eu trabalho numa empresa. Eu tenho uma dificuldade com horários, que é uma barreira difícil de ser vencida, mas, enfim, no tocante as ATPC (...), entendo que esse é um espaço extremamente rico! Se eu tivesse a oportunidade de participar regularmente eu o faria (...). No entanto, todas as vezes que tenho a possibilidade de participar eu venho! Aliás, eu prefiro estar aqui a estar nas ATPC de outras escolas. Se eu tivesse essa possibilidade faria isso com certeza! ... (transcrição da ATPC de 06/06/2013)

Outro professor que já estava desde 2009 na escola como professor categoria $\mathrm{O}$, com interrupções e intervalos de tempo, só passou a frequentar as ATPC na escola em 2013. Na rede estadual paulista, quando o professor leciona em mais de uma unidade escolar, o mesmo deve participar, preferencialmente, das ATPC na escola em que tem maior carga horária, o que no caso específico deste professor só aconteceu no ano de 2013.

Esses professores, como tantos outros, completam sua jornada em várias escolas. Essa é uma condição de trabalho recorrente devido aos baixos salários. Segundo dados da pesquisa de Alves e Pinto (2011), 23,8\% de professores das séries iniciais do ensino fundamental trabalham em mais de uma escola, e esse número vai aumentando progressivamente: $39,6 \%$ dos professores das nas séries finais do ensino fundamental e $44,5 \%$ dos professores do ensino médio dividem seu tempo entre várias escolas.

Os autores problematizam, ainda, que a atividade docente não se limita a dar aulas, exigindo do professor horas de planejamento de aulas, preparação de materiais, correção de atividades, entre outras. Eles exemplificam a dificuldade de um professor de Física, por exemplo, atingir uma jornada semanal de 40 horas/aula. Considerando que ele tem duas aulas por semana, precisará de 20 turmas para completar essa jornada, o que corresponde a 800 alunos, supondo-se uma média de 40 alunos por turma. Essas 20 turmas, provavelmente, estarão distribuídas em várias escolas. p.606),

No entanto, como discutido por Paro (2012,

a gestão do tempo dedicado ao trabalho escolar refere-se à necessária consideração de que o trabalho do professor não se restringe à atividade na situação de ensino, mas exige horários, incluídos em sua jornada de trabalho, nos quais ele possa, na integração com seus colegas, planejar $e$ avaliar seu trabalho, receber assessoria pedagógica (inclusive por meio de cursos e outros programas idealizados para esse fim), estudar, acompanhar e orientar grupos de estudantes, discutir questões do ensino e da gestão escolar, realizar contatos com a comunidade externa à escola, bem como outras atividades que jamais poderão ser realizadas se o trabalho do professor for entendido como sendo limitado pelas paredes de uma "sala de aula".

Importante também é destacar que alguns deles eram ainda estudantes de licenciatura, o que foi o caso de dois professores desse grupo. A falta de professores nas escolas está diretamente relacionada à atratividade da carreira. Gatti et al. (2010), a partir de extensa pesquisa realizada com estudantes concluintes do Ensino Médio sobre suas percepções a respeito da carreira docente, indicam que a diminuição da procura pela profissão de professor decorre da desvalorização associada a fatores como a massificação do ensino, a feminização do magistério, condições de trabalho, baixos salários, precarização e flexibilização do trabalho docente, entre outros. Apenas 2\% (31 de 1501 alunos) que responderam ao questionário aplicado indicaram alguma licenciatura como primeira opção.

Em face da escassez de professores, a rede estadual paulista, na ausência de professores habilitados atribuem-se classes e aulas para estudantes matriculados em cursos de licenciatura plena na área da disciplina que se encontrem 
cursando qualquer semestre e que tenham concluído no mínimo um semestre do curso (SÃO PAULO, 2013).

Nessas condições - ausências, falta de continuidade, interrupções, jornada sobrecarregada, pouca familiaridade com a escola etc. -, apesar do interesse e disponibilidade dos professores, não foi possível aprofundar a discussão definida conjuntamente no início do semestre e tampouco construir uma intervenção. Como referido pelo PC, a rotina de muitos professores constituiu obstáculo para o desenvolvimento de uma ação mais integrada:

Muitos aqui ministram aulas só à noite, então o tempo [de encontro e troca] é mais curto, porque há menos salas. Muitos professores vêm de segunda e quarta $e$ outros de terça e quinta. Então, o tempo é mais curto para se montar alguma coisa. A aceitação desses professores se torna difícil, é preciso ter um jogo de cintura muito maior do que com relação ao pessoal da manhã. Mas, nós precisamos começar a caminhar nesse sentido [da articulação dos conteúdos das disciplinas e elaboração de um projetol (transcrição da ATPC de06/06/2013).

O foco das discussões desse grupo foram as culturas juvenis, tema sugerido pelo PC e pela pesquisadora, a fim de problematizar o que significava ser jovem e sua relação com a escola. A sugestão buscava atender à necessidade desses professores, que se queixavam de que os alunos do Ensino Médio pareciam desmotivados, apáticos, indiferentes aos conteúdos das disciplinas e a um projeto de futuro.

Reconhecendo que seria importante compreender o que pensam os jovens e como se sentem, foram lidos dois textos de Juarez Dayrell (2003, 2007) que mostram uma série de imagens que interferem na maneira como compreendemos os jovens. Segundo o autor (2003), há três imagens bastante marcantes sobre os jovens: a imagem da juventude vista na sua condição de transitoriedade, na qual o jovem é um "vir a ser" que não tem presente e sim um futuro; a imagem romântica da uma juventude associada à liberdade e ao prazer; a imagem da juventude como momento de crise e de conflitos. Para Dayrell (2003), essas imagens estão calcadas em modelos socialmente construídos que nos compelem a analisar os jovens de forma negativa, com ênfase em padrões de um determinado modelo de "ser jovem". "Dessa forma, não conseguimos apreender os modos pelos quais os jovens, principalmente se forem das camadas populares, constroem as suas experiências" (p.41). Diante desses modelos, Dayrell (2007, p.1107) questiona em que medida a escola "faz" a juventude, "privilegiando a reflexão sobre as tensões e ambiguidades vivenciadas pelo jovem, ao se constituir como aluno num cotidiano escolar que não leva em conta a sua condição juvenil".

A professora Suzy reflete sobre as dificuldades e desafios a serem enfrentados:

Acho que poderíamos pensar sobre todas essas coisas [falta de interesse dos alunos]. Porque, pessoal, serei sincera: essa é a pedra em nosso sapato. Boa vontade $e$ entusiasmo nós temos. Em vista disso, dessa pedra no sapato, poderíamos pensar em coisas que seriam interessantes de construirmos juntos (transcrição da ATPC de 11/04/13).

Ao longo desse semestre nenhum projeto foi construído e as ATPC sobre a discussão das culturas juvenis não repercutiu na (re)elaboração do PPP. Observamos que nesse cenário estruturado por limites nas condições de trabalho constitui um desafio enorme garantir e apoiar a participação e engajamento dos professores nas ATPC.

\section{Considerações finais}

Concordamos com Paro (2012, p.858) quando ele diz que "uma reformulação da estrutura da escola fundamental com vistas a adequá-la ao oferecimento de uma educação como prática democrática não pode deixar de considerar a forma como se realiza o trabalho docente".

A prática democrática sustentada pelo trabalho coletivo e que orienta a (re)elaboração do PPP, como se pode observar, tem profundas relações com as condições de trabalho.

Quando os professores, como os do Grupo A, são efetivos e estáveis, têm sua jornada completa na escola, encontram-se regularmente e participam das ATPC completas, há emergência de possibilidade de formação e intervenção. Nessas condições o trabalho coletivo é fortalecido pelo diálogo orientado para a compreensão dos pontos de vista e ajuda mútua; pela socialização e revisão das práticas individuais e coletivas; pela insistência de perguntas que pautam a interação entre os professores, exigindo o reconhecimento, a implicação e a revisão de suas posições. Nessas mesmas condições, a teoria pode ser assumida como material que favorece a reflexão e o registro como oportunidade de reflexão e partilha. 

projeto político-pedagógico na escola básica

A falta dessas condições repercute como impedimento para a organização do trabalho coletivo. A jornada distribuída em muitas escolas, o cumprimento das ATPC em uma escola em detrimento das outras, a descontinuidade da participação nesses encontros, a forma de contratação e falta de estabilidade, falta de convivência com os colegas etc. apresentam-se como limites a serem considerados e que não podem ser atribuídos como responsabilidade dos professores.

As reformas educativas dos anos de 1990, associadas aos critérios de eficácia e produtividade, como apontado por Assunção e Oliveira (2009, p.351), têm transferido responsabilidades do âmbito central para as escolas, exigindo delas a "capacidade de resolver localmente os problemas encontrados, refletir sobre a sua realidade e trabalhar de forma coletiva e cooperativa".

Isso tem sido feito sem que estejam garantidas outras condições na forma de contratação, remuneração, carreira e estabilidade, bem como de participação nas ATPC.

A reelaboração do PPP supõe continuidade de trabalho, construção de vínculos de confiança e sentimento de pertencimento, elaboração de práticas coletivas e reflexão permanente a respeito do trabalho desenvolvido.

Para responder à formação de jovens leitores que resistam a processos de marginalização e experienciem a imaginação, autonomia e cidadania (PETIT, 2009), bem como promover as culturas juvenis na escola (DAYRELL, 2007), há um longo caminho a ser percorrido. Isso não será possível, contudo, fora do contexto do trabalho coletivo e da orientação do PPP discutido, realizado e registrado.

\section{Referências}

ALARCÃO, Isabel. Escola reflexiva e supervisão: uma escola em desenvolvimento e aprendizagem. Porto: Porto Editora, 2000.

ALVES, Thiago; PINTO, José M. R. Remuneração e características do trabalho docente no Brasil: um aporte. Cadernos de Pesquisa, v.41, n.143, maio/ago, 2011.

ASSUNÇÃO, Ada A.; OLIVEIRA Dalila A. Intensificação do trabalho e saúde dos professores. Educação e Sociedade, Campinas, v. 30, n. 107, p. 349-372, maio/ago. 2009.
BARROSO, João. Formação, projecto e desenvolvimento organizacional. In: CANÁRIO, R. (org.). Formação e situações de trabalho. Porto: Porto Editora, 2003.

A escola tem futuro? Das promessas às incertezas. Porto Alegre: Artmed, 2006.

Fazer da formação um projeto: mudar as escolas ou os centros de formação? Lisboa: IIE, 2001.

CUNHA, Renata C. O. B.; OMETTO, Cláudia B. C. N. O trabalho coletivo na escola: o projeto políticopedagógico como pauta de formação. Educação, Porto Alegre, v. 36, n. 3, p. 402-411, set./dez. 2013.

CUNHA, Renata C. O. B.; PRADO, Guilherme V.T. Formação centrada na escola, desenvolvimento pessoal e profissional de professores. Revista de Educação PUC-Campinas, Campinas, Programa de Pós-Graduação em Educação da Pontifícia Universidade Católica de Campinas, n. 28, p. 103113, jan.-jun. 2010.

DAYRELL, Juarez. O jovem como sujeito social. Revista Brasileira de Educação, Rio de janeiro, v.24, p.40-52, set./dez. 2003.

A escola "faz" as juventudes? Reflexões em torno da socialização juvenil. Educação e Sociedade, Campinas, v. 28, n. 100 - Especial, p.1105-1128, out. 2007.

FREITAS, Maria T. A. A abordagem sóciohistórica como orientadora da pesquisa qualitativa. Cadernos de Pesquisa, n. 116, p 21-39, jul. 2002.

FUllan, Michael; HARGREAVES, Andy. Por que é que vale a pena lutar? $O$ trabalho de equipa na escola. Porto: Porto Editora, 2001.

GATTI, Bernadete A. et. al. A atratividade da carreira docente no Brasil. Estudos \& Pesquisas Educacionais, São Paulo, n. 1, p. 139-209, mai. 2010.

GERALDI, Corinta M. G. Currículo em ação: buscando a compreensão do cotidiano da escola básica. Pro-Posições, Campinas, v. 5, n. 3, p.111132, nov. 1994.

GIOVANI, Luciana M. Do professor informante ao professor parceiro: reflexões sobre o papel da universidade para o desenvolvimento profissional de professores e as mudanças na escola. Caderno 
CEDES, Campinas, Centro de Estudos Educação e Sociedade, v.19, n.44. abr. 1998.

EZPELETA, Justa; ROCKWELL, Elsie Pesquisa participante. São Paulo: Cortez, 1986.

HELlER, Agnes. O Cotidiano e a História. $6^{\mathrm{a}}$ ed. São Paulo: Paz e Terra, 2000.

HYPOLITO, Álvaro M.; IVO, Andressa A. Políticas curriculares e sistemas de avaliação: efeitos sobre o currículo. Revista e-Curriculum, São Paulo, Programa de Pós-Graduação Educação: Currículo da Pontifícia Universidade Católica de São Paulo, v.02, n.11, p.376-392, ago. 2013

KRAMER, Sonia. Leitura e escrita como experiência: seu papel na formação de sujeitos sociais. Presença Pedagógica, Belo Horizonte, Editora Dimensão, v.6, n.31, p.17-27, jan.-fev. 2000.

MIGLIAVACCA, Adriana. Condições de trabalho do professor. In: OLIVEIRA, Dalila A.; DUARTE, Adriana M. C.; VIEIRA, Lígia M. F. DICIONÁRIO: trabalho, profissão e condição docente. Belo Horizonte: UFMG/Faculdade de Educação, 2010. CDROM.

OLIVEIRA, Dalila A.; ASSUNÇÃO, Ada A. Condições de trabalho docente. In: In: OLIVEIRA, Dalila A.; DUARTE, Adriana M. C.; VIEIRA, Lígia M. F. DICIONÁRIO: trabalho, profissão e condição docente. Belo Horizonte: UFMG/Faculdade de Educação, 2010. CDROM.

PARO, Vitor H. Trabalho docente na escola fundamental: questões candentes. Cadernos de Pesquisa, v.42, n.146, p.586-611, maio/ago. 2012.

PEREIRA, Sueli M. Políticas de Estado e organização político-pedagógica da escola: entre o instituído e o instituinte. Ensaio: Avaliação e Políticas Públicas em Educação, Rio de Janeiro, v. 16, n. 60, p. 337-358, jul./set. 2008.

PETIT, Michéle. Os jovens e a leitura: uma nova perspectiva. 2a ed. São Paulo: Editora 34, 2009.

PETIT, Michéle. A arte de ler: ou como resistir à adversidade. São Paulo, Editora 34, 2010.

SADALLA, Ana M. F. A.; SÁ-CHAVES, Idália. Constituição da reflexividade docente: indícios de desenvolvimento profissional coletivo. Revista ETD - Educação Temática Digital, Campinas, Faculdade de Educação da Universidade Estadual de Campinas, v.9, n.2, p.189-203, jun. 2008.

SÃO PAULO. Secretaria da Educação. Resolução SE 75, de 28-11-2013. Dispõe sobre o processo anual de atribuição de classes e aulas ao pessoal docente do Quadro do Magistério. Disponível em: http://siau.edunet.sp.gov.br/ItemLise/arquivos/75_1 3.HTM?Time=28/09/2014\%2006:46:54 .

SOLIGO, Rosaura. Para elaborar o registro do projeto político-pedagógico. Subsídio de orientação para formação dos gestores das Secretarias Municipais da Educação de Rio BrancoAC e de Aracruz-ES. São Paulo: Abaporu, 2007.

VEIGA, Ilma P.A. Inovações e projeto políticopedagógico: uma relação regulatória ou emancipatória? Cadernos CEDES, Campinas, v.23, n.61, p. 267-281, dez. 2003.

ZANON, A. et al. Leitura como prática cultural e sustentabilidade. In: VI Simpósio de Práticas Educativas na Educação Básica, 2012, PiracicabaSP. Anais do VI Simpósio de Práticas Educativas na Educação Básica. Piracicaba: Colégio Piracicabano, 2012, p.1-8.

\section{Sobre a autora:}

Renata Cristina Oliveira Barrichelo Cunha: Graduada em Pedagogia pela Pontifícia Universidade Católica de São Paulo (1990) e Doutora em Educação pela Universidade Estadual de Campinas (2006). É professora do Programa de Pós-Graduação em Educação da Universidade Metodista de Piracicaba (UNIMEP).

Artigo recebido em outubro de 2014.

Artigo aprovado em abril de 2015. 